\title{
Hormonal regulation of ICAM-1 gene expression in thyroid cells, FRTL-5
}

\author{
Bong Soo An, ${ }^{1}$ Bon Jeong Ku, ${ }^{1}$ \\ So Young Park, ${ }^{1}$ Jae Kyu Shin, ${ }^{1}$ \\ Jin Hong Lee, ${ }^{1}$ Young Kun Kim, ${ }^{1}$ \\ Minho Shong ${ }^{1,2}$ and Heung Kyu Ro ${ }^{1}$ \\ 1 Department of Internal Medicine, School of Medicine,
Chungnam National University, Taejon 301-040, Korea
2 Corresponding author \\ Accepted 29 January 1997
}

Abbreviations: TSH, thyroid stimulating hormone; ICAM-1, intercellular adhesion molecule-1; MHC, major histocompatibility complex; TNF- $\alpha$, tumor necrosis factor $\alpha$

\begin{abstract}
Our previous works have shown that human thyroid follicular cells from Graves' disease and FRTL-5 rat thyroid cells express the intercellular adhesion molecule-1 (ICAM-1) molecule and its expression is upregulated by several cytokines, interferon- $\gamma$, tumor necrosis factor- $\alpha$, interleukin-1 $\beta$ and interleukin-6. We used FRTL-5 cells which show hormonal dependence of growth and function for the study of hormonal regulation of ICAM-1 gene. We studied ICAM-1 mRNA expression and promoter regulation after cloning of rat ICAM-1 promoter. We found very interesting findings that thyroid stimulating hormone (TSH) and forskolin downregulates steady state MHC class I and ICAM-1 mRNA levels in FRTL-5 cells; furthermore, TSH/cAMP inhibit cytokines (interferon$\gamma$, tumor necrosis factor- $\alpha$ )-mediated maximal ICAM-1 mRNA expression. In addition, hydrocortisone and insulin differentially regulate the ICAM-1 mRNA levels; hydrocortisone markedly suppresses the mRNA level but insulin partially recovers hydrocortisone mediated ICAM-1 suppression. The interferon- $\gamma$ and tumor necrosis factor- $\alpha$ increases full ICAM-1 promoter (pCAM-1822) activity and this cytokine mediated increase of the promoter activity is also inhibited by TSH and forskolin. Thus TSH/cAMP pathways play roles as a antagonistic action for maximal expression of ICAM-1 gene by these cytokines. We propose this TSH action is one of physiologic mechanisms to preserve self tolerance in face of abnormal cytokine challenges in systemic inflammatory condition or acute phase response.
\end{abstract}

Keywords: thyrotropin, CAMP, rat ICAM-1, thyroid, FRTL-5, cytokines

\section{Introduction}

The pathogenesis of human and animal autoimmune thyroid diseases is still obscure. In current concepts, several immunological and target cell factors are discussed as initiative abnormalities in the development of autoimmune thyroid disease. Recent several reports suggested that the target cell factors, especially presence or absence of major histocompatibility complex (MHC) class I or class II expression is critical for the development of particular autoimmune diseases, e.g., autoimmune blepharitis (Chan et al., 1995), systemic lupus erythematosus (Mozes et al., 1993; Chan et al., 1995) and Graves like disease (Shimojo et al., 1996).

Our previous studies of the regulation of thyrotropin receptor and $\mathrm{MHC}$ class I gene in the rat FRTL- 5 thyroid cell revealed that TSH/CAMP actively suppresses the expression of these molecules at the transcriptional level (Ikuyama et al., 1992; Saji et al., 1992a-c; Giuliani et al., 1995). It was additionally interesting that MHC class I expression was decreased by insulin, IGF-1, serum and hydrocortisone (Saji et al., 1992a). Most of hormones or growth factors associated with maximal FRTL-5 thyroid cell growth suppressed MHC class I gene expression (Saji et al., 1992a-c; Giuliani et al., 1995). These observations led to the hypothesis that hormonal suppression of $\mathrm{MHC}$ class I gene expression maintains low class I levels, thereby preserving self tolerance in the face of hormone action to increase the expression of thyroid specific thyroglobulin, thyroperoxidase or ubiquitous genes during TSH induced growth and function (Kohn et al., 1995).

On the other hand, costimulatory signals during immune recognition seems to be pivotal in determining whether recognition of target cells by $T$ lymphocytes leads to $T$ cell activation or anergy (Thomson, 1995). Currently several molecules and its pathways are identified as important costimulatory signals (Sharpe, 1995). The roles of B7-1 and B7-2 were known as very strong costimulatory molecules in tumor cytotoxicity and other autoimmune models (Chan et al., 1995). But B7-1 molecules were not detected in Graves' thyroid cells and B7-2 is not studied yet (Tandon et al., 1994; Weetman, 1994).

Intercellular adhesion molecule-1 (ICAM-1) is a transmembrane glycoprotein that belongs to the immunoglobulin supergene family and plays role as a counter receptor for leukocyte integrins and T cell CD43 
(Springer, 1990; Rothlein et al., 1991). The binding of ICAM-1 to its counter receptor plays critical role in the migration of lymphocytes into inflamed tissues and strengthens effector-target interactions (Rothlein et al., 1991; Springer, 1990). The thyroid cells from Hashimoto disease and Graves' disease not only show higher level of expression of ICAM-1 but also it mediates increased lymphocyte binding to the thyroid cells in vitro (Martin et al., 1990; Weetman et al., 1990; Shong et al., 1994). The rat ICAM-1 antibody administrations inhibit the development of antigen-induced rat autoimmune thyroiditis. We have shown that the ICAM-1 is basally expressed in FRTL- 5 cells and its expression is regulated by cytokines.

We tried to extend the hypothesis that hormones and growth factors are involved in the negative regulation of autoantigen TSH receptor (Saji et al., 1992c), MHC class I gene (Kohn et al., 1995) to thyroid costimulatory molecule, in particular ICAM-1 gene expression. In this study we identified a negative regulation of ICAM-1 gene expression by several hormones, hydrocortisone, insulin and TSH. Furthermore, we showed some findings that hormones also suppress the cytokine induced maximal expression of ICAM-1 gene.

\section{Materials and Methods}

\section{Materials}

Bovine TSH was a highly purified preparation obtained from the NIH distribution program (NIDDK bTSH I-1; 30 $\mathrm{U} / \mathrm{mg}$ ) or was the purified preparation as previously described (Ikuyama et al., 1992; Saji et al., 1992a; Kohn et al., 1995). Insulin and hydrocortisone were purchased from Sigma Chemical Co. (St louis, MO). $\left[\alpha^{-32} \mathrm{P}\right] \mathrm{dCTP}$ $(3000 \mathrm{Ci} / \mathrm{mmol})$ were obtained from DuPont/New England Nuclear (Boston, MA).

\section{Cell culture}

The FRTL-5 rat thyroid cells (American Type Culture Collection; CRL 8305; Interthyr Research Foundation, Baltimore, MD) used in this report were a fresh subclone (F1) with all properties previously detailed (Saji et al., 1992a-c). During the course of these experiments they did not proliferate in the absence of $\mathrm{TSH}$, yet remained viable for prolonged periods in its absence. They were grown in Coon's modified F12 medium supplemented with $5 \%$ calf serum, $1 \mathrm{mM}$ nonessential amino acids (Gibco), and a mixture of six hormones including TSH (10 mM) as described (Saji et al., 1992a), They were provided with fresh medium every 2 or 3 days, and as appropriate individual experiments, cells were shifted to $4 \mathrm{H}$ medium (no $\mathrm{TSH}$, no insulin) or to $3 \mathrm{H}$ medium (no $\mathrm{TSH}$, no insulin, no hydrocortisone). FRT rat thyroid cells, although derived from early parental FRTL cell cultures, have no functional TSH receptor and no TSH receptor RNA. They were maintained in Coon's modified F12 medium containing $5 \%$ calf serum.

\section{RNA isolation and analysis}

Total cellular RNA and poly $(A)^{+}$RNA were isolated by standard procedures (Saji., 1992a). Northern blot analysis were performed as described (Saji et al., 1992a); final washes were carried out at $65^{\circ} \mathrm{C}$ in $1 \times$ SSPE (150 mM NaCl, $10 \mathrm{mM} \mathrm{NaH} \mathrm{PO}_{4}, 1 \mathrm{mM}$ EDTA, $\mathrm{pH}$ 7.4). The rat TSH receptor probe was the purified insert fragment of clone T8AFB, spanning residues -54 to 2780 of the reported sequence of the rat TSH receptor gene. The $\mathrm{MHC}$ class I probe was the $1.0 \mathrm{~kb}$ Hpall fragment of $\mathrm{pH} 7$ clone which spans the entire CDNA insert. The rat ICAM-1 probe was whole cDNA sequence which was cloned in EcoR1 site of pUC19 plasmid. Rat beta-actin probe was kindly provided by $B$. Paterson (National Cancer Institute, NIH, U.S.A.). All probes were radiolabeled by random priming method.

\section{Construction of reporters of rat ICAM-1 promoter and stable transfection analysis}

To test the ICAM-1 promoter activity in FRTL- 5 cells, the rat ICAM-1 promoter was cloned into multicloning site, Bg/ll and HindIII of luciferase reporter vector, pGL2 basic (Promega, WI). The full construct named pCAM1822 was used for the measurement of promoter activity in different hormonal condition.

Using a electroporation, we made stable FRTL-5 transfectant cells with pGL2-basic based constructs containing luciferase gene downstream of the $5^{\prime}$ flanking region of rat ICAM-1 gene. It contains the nucleotide from -1822 to -1 of the start of translation. Near confluent cells in $6 \mathrm{H}$ medium were cotransfected with $20 \mu \mathrm{g}$ of plasmid DNA and $10 \mu \mathrm{g}$ of pRc. pRc is derived from $\mathrm{pRc} / \mathrm{CMV}$ which contains human early cytomegalovirus promoter and neomycin gene. pRc does not contain a portion of human early cytomegalovirus promoter. After 7 days, $400 \mu \mathrm{g} / \mathrm{ml}$ of G418 (Life Science Technologies, Paolo Alto, CA) was added to the medium and after 3 weeks the G418-resistant colonies were pooled and used for experiments herein. Luciferase assays were performed as described previously (Giuliani et al., 1995).

\section{Other Methods and Statistical Significance}

Protein concentration was determined by Bradford's method (Bio-Rad, Hercules, CA). Recrystallized bovine serum albumin was used as a standard. All experiments were repeated at least three times with different batches of cells. Significance, $P<0.005$, was determined by two way analysis of variance. 


\section{Results}

\section{Expression of ICAM-1 mRNA in FRTL-5, FRT and BRL cells}

ICAM-1 mRNA is easily detected by Northern analysis using total RNA from FRTL-5 cells regardless of culture conditions (Figure 1,2). The molecular mechanism of steady expression of ICAM-1 gene in FRTL- 5 cells is still unclear. The ICAM-1 expression is mainly regulated on the transcriptional level and transcription can be increased by several cytokines and growth factors. Many growth factors and cytokines such as insulin-like growth factor, epidermal growth factor, fibroblast growth factor, transforming growth factor $\beta$, ANP, interleukin-6, interleukin- 8 are produced by autocrine mechanism in continuously growing FRTL- 5 cells. It is possible that the basal expression of ICAM-1 mRNA is related to some factors of above autocrine growth factors, cytokines, and exogenous serum. These growth factors and serum may activate some transcription factors related to expression of cytokine-inducible and acute phase response genes.

The transcripts of rat ICAM- 1 showed a single band of $2.6 \mathrm{~kb}$ in length (Shong et al., 1994a). The FRT cells which is come from early FRTL cell culture did not show

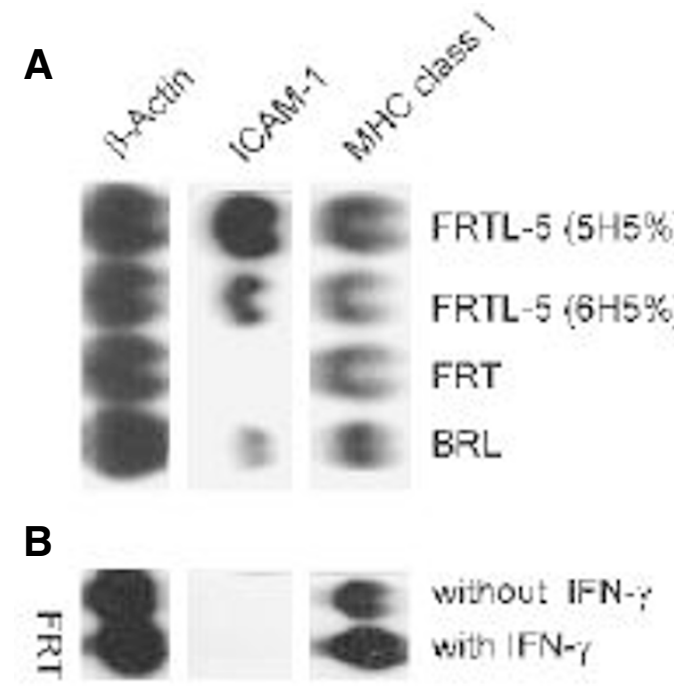

Figure 1. Expression of ICAM-1 and MHC class I mRNA in FRTL-5 cells ( $5 \mathrm{H} 5 \%, 6 \mathrm{H} 5 \%$ ), FRT and Buffalo Rat Liver (BRL) cells. After growth to near confluence, the monolayer of FRTL-5, FRT and BRL cells, with low passage number $(<20)$ were maintained with adequate medium. RNA was isolated and subjected to Northern analysis using probes for MHC class I, ICAM- 1 and rat $\beta$-actin. $\ln (\mathbf{A})$ a representative Northern analysis from one experiment is presented which contained $20 \mu \mathrm{g}$ of total RNA/lane. In (B) FRT cells were treated with interferon- $\gamma(100 \mathrm{U} / \mathrm{ml})$ and RNA was isolated from untreated control and interferon $\gamma$ treated cells.
ICAM-1 mRNA with usual Northern analysis (Figure 1A, $B)$. This cell was known as a thyroid lineage cells because they express a thyroid specific transcription factor, Pax8, a paired box protein (Shong et al., 1997). But FRT does not express functional TSH receptor or TSH receptor mRNA, so it does not show any functional growth related to TSH. Furthermore FRT does have a defect in expression of a homeodomain transcription factor, NKx2.1 (thyroid transcription factor-1) which is related to thyroid specific expression of thyroglobulin and thyroperoxidase (Shong et al., 1997). With this study, we added a finding that ICAM-1 was not expressed in FRT cells as another characteristics of its biology. Interferon- $\gamma$ is a very strong inducer of ICAM-1 mRNA in FRTL-5 cells (Shong et al., 1994b) and other endothelial cell types, but the inducibility of ICAM-1 mRNA in FRT cell was negligible (Figure 1B). We guess the molecular mechanism of absence of ICAM1 induction in FRT cell is related to defects in signal transduction pathways or in transcription factors which is critical for basal expression of ICAM-1 gene. The nonspecific profound methylation of promoter of ICAM-1 gene is an another possible mechanism for the defect of FRT cell. We used BRL (buffalo rat liver) cells for the nonthyroid control cell, which also express ICAM-1 mRNA in usual culture condition.

\section{Hydrocortisone, insulin, and TSH differentially regulate the ICAM-1 gene expression}

We found differential regulation of ICAM-1 mRNA levels in different culture conditions in FRTL-5 cells. The cells maintained at $3 \mathrm{H}$ (no hydrocortisone, no insulin, no TSH) condition showed the highest expression level compared to $4 \mathrm{H}, 5 \mathrm{H}$, or $6 \mathrm{H}$ medium (Figure 2). We observed very implicative findings with this experiment (Figure 2): hydrocortisone markedly decreased the

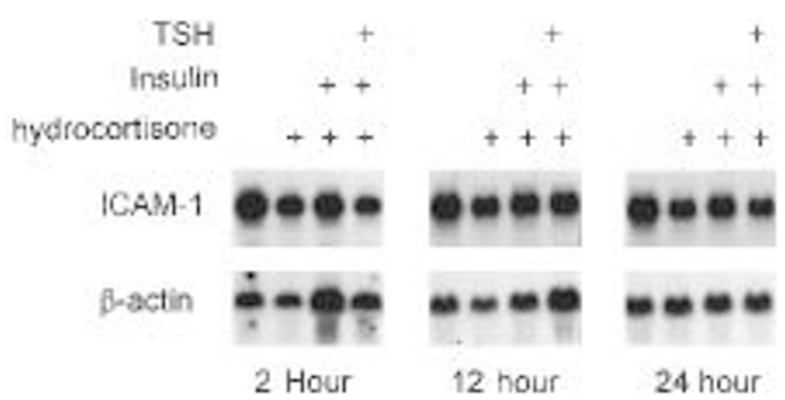

Figure 2. Effect of hydrocortisone, insulin and TSH on ICAM-1 mRNA levels in rat FRTL-5 thyroid cells. After growth to near confluence, the monolayer FRTL-5, with low passage number $(<20)$ were maintained with $3 \mathrm{H} 5 \%$ medium which does not contain hydrocortisone, Insulin and TSH for 6 days before addition of those hormones. RNA was isolated and subjected to Northern analysis using probes for ICAM-1 and rat $\beta$ actin 
ICAM-1 mRNA and insulin partially recovered the hydrocortisone-induced repression. Otherwise, TSH, which is important in growth and function of FRTL-5 cells, could independently downregulate the ICAM-1 mRNA levels; TSH could decrease ICAM-1 mRNA from FRTL-5 cells in $3 \mathrm{H} 5 \%, 4 \mathrm{H} 5 \%, 5 \mathrm{H} 5 \%$ (data not shown). We used forskolin $(10 \mu \mathrm{M})$ to test whether it could mimic the action of TSH on ICAM-1 mRNA (Figure 3, lane 9). Forskolin also decreased ICAM-1 mRNA levels regardless of culture condition (data not shown). TSH could decrease the MHC class I mRNA but it required the insulin and serum for maximal repression (Saji et al., 1992a). It may suggest that different molecular mechanisms are involved in TSH/cAMP-induced repression of both $\mathrm{MHC}$ class I and ICAM-1 gene. TSH suppression of ICAM-1 expression is very interesting because the TSH is a major physiologic mechanism to preserve self tolerance by decreasing MHC class I and thyroid autoantigen during $\mathrm{TSH}$ derived thyrocyte growth.

\section{Tumor necrosis factor $\alpha$ (TNF- $\alpha$ ) and interferon- $\gamma$ increase ICAM-1 expression}

As is the case of endothelial cells and immune cells, ICAM-1 mRNA levels are upregulated by several cytokines, such as TNF- $\alpha$, interferon- $\gamma$ and interleukin- 6 in FRTL-5 thyroid cells. However, the protein kinase C stimulator, phorbol ester, are known as strong ICAM-1 inducer through activation of protein kinase $C$ in a number of cell types with unknown mechanism, but in thyroid FRTL- 5 cells it did not induce ICAM- 1 expression. This finding suggest that ICAM-1 expression is regulated by tissue-specific mode (Figure 3, lane 4).

It is known that TNF- $\alpha$ mediated upregulation of proinflammatory genes involves activation of the transcription factors AP1 and NF- $\mathrm{KB}$. Induction of ICAM1 mRNA by TNF- $\alpha$ is a very rapid phenomenon peaking at 2 or $3 \mathrm{~h}$ after TNF- $\alpha$ treatment in FRTL- 5 cells maintained with $5 \mathrm{H} 5 \%$ medium (data not shown). The ICAM$1 \mathrm{mRNA}$ level was gradually decreased after $3 \mathrm{~h}$ of TNF- $\alpha$ challenge but its level still maintained high level over $24 \mathrm{~h}$ compared to steady state (Figure 3, lane 2).

Interferon- $\gamma$ upregulates both ICAM- 1 mRNA and protein synthesis in many cell types. We have checked interferon- $\gamma$ effect on ICAM-1 mRNA synthesis with optimal dose $(100 \mathrm{U} / \mathrm{ml})$ enough for induction of $\mathrm{MHC}$ class I gene. Interferon- $\gamma$ showed over 3-fold increase of its RNA level compared to steady state.

\section{TSH/forskolin inhibits maximal expression of ICAM-1 by TNF- $\alpha$ and interferon- $\gamma$}

We have described that TNF- $\alpha$ and interferon- $\gamma$ enhanced the expressoin of ICAM-1 in FRTL-5 cells. To determine whether TSH-induced signal pathway modulates those cytokine-induced ICAM-1 expression in cultured FRTL-5 cells, monolayers were treated with
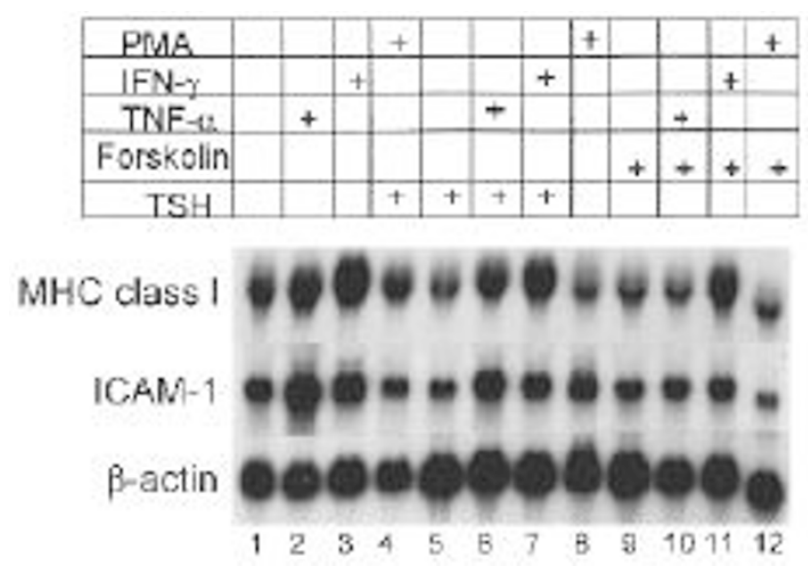

Figure 3. Effects of TSH and forskolin on ICAM-1 mRNA levels after treatment of cytokines (interferon- $\gamma$, TNF- $\alpha$ ) and PMA onto FRTL- 5 thyroid cells. After growth to near confluence, the FRTL-5 cells, with low passage number $(<20)$ were maintained with $5 \mathrm{H} 5 \%$ medium which does not contain TSH for 6 days before addition of TSH (10 $\mathrm{mM})$, forskolin (10 $\mu \mathrm{M})$, interferon- $\gamma(100 \mathrm{U} / \mathrm{ml})$, TNF- $\alpha(100 \mathrm{ng} / \mathrm{ml}), \mathrm{PMA}(50 \mathrm{nM})$. RNA was isolated and subjected to Northern analysis using probes for MHC class I, ICAM- 1 and rat $\beta$-actin.

TSH and TNF- $\alpha$ or interferon- $\gamma$. In addition, cells were also treated with forskolin which directly activates adenyl cyclase and cytokines. RNA was isolated and ICAM-1 expression was determined by Northern blot analysis (Figure 3 ). The steady state level of ICAM-1 expression was decreased by TSH and forskolin (Figure 3 , lanes 5,9$)$ and increased by interferon- $\gamma$ and TNF- $\alpha$ (Figure 3, lanes 2, 3). Interferon- $\gamma$ induced expression of ICAM-1 was inhibited in FRTL-5 cells treated with TSH and forskolin (Figure 3, lanes 5, 9). We could observe a similar result in interferon- $\gamma$-treated cells: TSH and forskolin suppress the enhanced expression of ICAM-1 by INF- $\gamma$.

\section{TSH and forskolin also suppress the ICAM-1 promoter activity}

We cloned the rat ICAM-1 promoter to check the hormonal regulation of ICAM-1 gene in rat thyroid cell line, FRTL-5. We placed the rat ICAM-1 5' upstream region from -1822 to -1 (pCAM-1822) -97 to -1 (pCAM97) in front of promoterless luciferase reporter gene construct, pGL2-basic. Following the stable transfection with pCAM-1822, pCAM-97 plasmid, FRTL-5 stable transfectant was exposed to TSH, forskolin, interferon- $\gamma$, and TNF- $\alpha$. The luciferase activity of the induced cells was compared to that of untreated cells and the results are shown in Figure 4 as fold induction. No inducibility by either cytokine and TSH was observed with the promoterless construct pGL2 nor with the shortest construct (pCAM-97), containing only the TATA box. The FRTL- 5 cells which was stably transfected with 


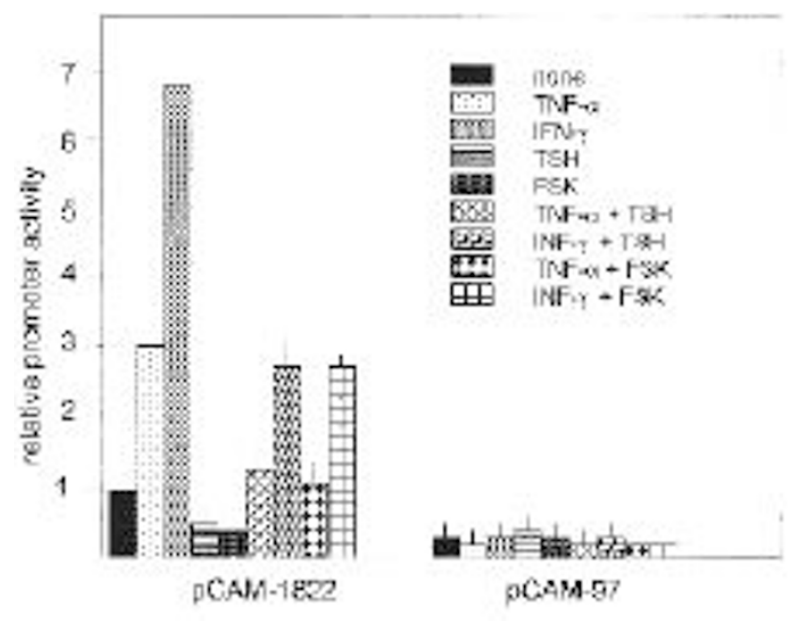

Figure 4. Effects of TSH, forskolin, and cytokines (interferon- $\gamma$, TNF- $\alpha$ ) on rat ICAM-1 promoter activity in FRTL- 5 thyroid cells which contained stably transfected rat ICAM-1 promoter construct plasmid, pCAM-1822, pCAM-97. FRTL-5 cells were transfected with pGL2-basic based constructs containing luciferase gene downstream of the $5^{\prime}$-flanking region of rat ICAM-1 gene, it contains the $-1822 \mathrm{bp}$ at the $5^{\prime}$ end and $-1 \mathrm{bp}$ the start of translation. Luciferase assays were performed as described previously. The value of luciferase activity from untreated pCAM-1822 was control for comparison of promoter activity from treated cells. All experiments were repeated at least 3 times and significance, $P<0.005$ was determined two way analysis of variance.

pCAM-1822 plasmid showed about 6-fold induction with interferon- $\gamma$ and a 3.5-fold induction with TNF- $\alpha$. TSH $(10 \mathrm{mM})$ and forskolin $(10 \mu \mathrm{M})$ decreased the promoter activity significantly. The stably transfected cells pretreated with $\mathrm{TSH}$ and forskolin showed significant less promoter activity after stimulation of those cells with interferon- $\gamma$ and TNF- $\alpha$. These findings suggest that $\mathrm{TSH}$, forskolin and cytokines are actively involved in transcriptional regulation of ICAM-1 gene expression.

\section{Discussion}

In many cell types, steady expression and cytokine modulation of ICAM-1 gene are studied intensively because its roles are very important in lymphocyte migration, target cell recognition and other cell to cell immunologic phenomena. We have recently shown that FRTL- 5 cells and human thyroid follicular cells from Graves' disease and Hashimoto disease express ICAM1 which is detectable by usual Northern blot analysis and immunocytochemistry (Shong et al., 1994b). We also suggested ICAM-1 on thyroid cells may be involved in inflammatory process during thyrocyte-directed autoimmune reaction (Lee et al., 1996).

Our previous studies of the regulation of $\mathrm{TSH}$ receptor and MHC class I gene in the rat FRTL-5 thyroid cells uncovered an important phenomenon (Saji et al., 1992a-c; Giuliani et al., 1995; Kohn et al., 1995): TSH/cAMP actively suppress the expression of TSH receptor and $\mathrm{MHC}$ class I at the transcriptional level. It was additionally interesting that $\mathrm{MHC}$ class I expression was decreased by insulin, insulin-like growth factor-1, serum and hydrocortisone (Saji et al., 1992). Most of hormones and growth factors associated with maximal FRTL-5 thyroid cell growth suppress MHC class I gene expression. These observations lead to the hypothesis that hormonal suppression of MHC class I gene expression maintains low MHC class I levels, thereby preserving self tolerance in the face of hormone action to increase the expression of thyroid specific thyroglobulin, thyroperoxidase during TSH induced growth (Shong et al., 1997). From the above data, TSH/cAMP-mediated negative regulation of ICAM-1 and $\mathrm{MHC}$ molecules are very implicative for the explanation of the pathogenesis of autoimmune thyroid disease.

Our observations that TSH, hydrocortisone and insulin (insulin recovers the hydrocortisone-mediated ICAM-1 suppression, but decrease mRNA independently in $3 \mathrm{H} 5 \%$ FRTL-5 cells) suppress ICAM-1 expression also support the above hypothesis. All the steroids dexamethasone and hydrocortisone inhibit induction of ICAM-1 by interleukin-1 on A549 cells, and an effect of dexamethasone on the transcriptional level (Voraberger et al., 1991) has been proposed using U937 cells and cotransfection of the glucocorticoid receptor together with reporter constructs into 293 cells resulted in repression of phorbol myristate acetate- and TNF- $\alpha$-induced promoter activity by dexamethasone. TNF- $\alpha$-mediated ICAM-1 induction was suggested to be inhibited by a functional antagonism between the p65 subunit of NF- $\mathrm{KB}$ and the ligand bound glucocorticoid receptor similar to the IL-6 gene which is also downregulated by glucocorticoids. Panettieri et al. (1995) have reported that treatment of airway smooth muscle cells with pharmacologic agents that increase intracellular CAMP inhibit TNF- $\alpha$ mediated induction of ICAM-1 and VCAM-1 and inhibit adhesion of activated T cells to TNF- $\alpha$ stimulated airway smooth muscle cells. In many cell types, TNF- $\alpha$ and interferon- $\gamma$ induce expression of various cell adhesion molecules, including ICAM-1 and VCAM-1. However the steady state level of ICAM-1 expression is relatively resistant to the suppression by intracellular cAMP. These observations are similar to our observations in FRTL- 5 cells.

The promoter of rat ICAM-1 gene has several regulatory elements for constitutive and stimulated expression. The interferon response elements and NF$\mathrm{kB}$ site is major regulatory elements for interferon induced ICAM-1 gene expression. TNF- $\alpha$ activates NF$\kappa B$ system to translocate $\mathrm{p} 50$ and p65 into nucleus in FRTL-5 cells (Taniguchi et al., 1997). We can presume the mechanism of TNF- $\alpha$-induced ICAM- 1 gene transcription should involve NF- $\kappa B$ activation. The 
signalling pathways mediating cellular responses to TNF are beginning to be elucidated. TNF- $\alpha$ signalling is initiated by interaction of TNF- $\alpha$ with two distinct cell surface receptor molecules, TNF-R55, TNF-R75 (Fier et al., 1991; Rothe et al., 1992; Tartaglia et al., 1992). While information about TNF-R75 is scarce, TNF-R55 has been shown to trigger specific signal cascades, including phospholipase A2, phosphatidylcholinespecific phospholipase $C$, protein kinase $C$, mitogen activated kinase (MAP kinase) and two distinct types of sphingomyelinase, a plasma bound neural and intracellular endo-/lysosomal type (Schutze et al., 1991, 1992a,b; Wiegmann et al., 1992, 1994; Heller et al., 1994). Thus, with our observation that TSH suppress TNF- $\alpha$ induced ICAM-1 gene expression, it is possible that in FRTL-5 cells the inhibitory effects of TSH on TNF- $\alpha$ action could result from a cross-talk with other second messengers and finally $\mathrm{TSH}$ delays or inhibits the activation of NF- $\mathrm{KB}$.

In fact, that upregulation of ICAM-1 by interferon- $\gamma$ requires both protein and mRNA synthesis suggesting that regulation of ICAM-1 expression occurs primarily at the transcriptional level. The action of interferon- $\gamma$ on transcription is mainly mediated by Stat (signal transducer and activation of transcription) proteins, p91 and p84 (Shuai et al., 1993; Ivashikiv, 1995; Wen et al., 1995). These Stat proteins are activated by various forms of Janus kinases that are coupled to interferon receptor. Recently it has been shown that Jak/Stat pathways are inhibited by activation of protein kinase $A$ in U266 cells (David et al., 1996). This finding suggests that suppression of interferon- $\gamma$-induced ICAM-1 expression by TSH may be mediated by blocking the Jak/Stat signal transductiuon pathway. This hypothesis is now being tested by ourselves.

\section{Acknowledgement}

This work was supported by the CNUH research fund and Alumni Fund of Department of Internal Medicine during the course of this project.

\section{References}

Caldenhoven, E., Liden, J., Wissink, S., Stolpe A, V., Raaijmakers, J., Koenderman, L., Oklet, S., Gustafsson, J. A. and Saag, P. T. V. (1995) Negative cross talk between RelA and the glucocorticoid receptor: A possible mechanism for the antiinflammatory action of glucocorticoids. Mol. Endocrinol. 9: 401-412

Chan, C. C., Gery, I., Kohn, L. D., Nussenblatt, R. B., Mozes, E. and Singer, D. S. (1995) Periocular inflammation in mice with experimental systemic lupus erythematosus. A new experimental blepharitis and its modulation. J. Immunol. 154: 4830-4835

David, M., Perticoin, E. III and Larner, A. C. (1996) Activation of protein kinase A inhibits interferon induction of the Jak/Stat pathway in U266 cells. J. Biol. Chem. 271: 45854588
Fier, W. (1991) Tumor necrosis factor. characterizaton at the molecular, cellular and in vivo level. FEBS Lett. 285:199-212

Giuliani, C., Saji, M., Napolitano, G., Palmer, L. A., Taniguchi, S.-I., Shong, M., Singer, D. S. and Kohn, L. D. (1995) Hormonal Modulation of major histocompatibilty complex class I gene expression involves an enhancer A binding complex consisting of Fra-2 and the p50 subunit of NF-KB. J. Biol. Chem. 270: 11453-11462

Harlan, D. M., Abe, R., Lee, K. P. and June, C. H. (1995) Potential roles of the B7 and CD28 receptor families in autoimmunity and immune invasion. Clin. Immunol. Immunopathol. 75: 99-111

Heller, R. A. and Kroenke, M. (1994) Tumor necrosis factor receptor mediated signalling pathways. J. Cell Biol. 126: 5-9

Ikuyama, S., Niller, H. H., Shimura, H., Akamizu, T. and Kohn, L. D. (1992) Characterization of the 5 '-Flanking region of the rat thyrotropin receptor gene. $\mathrm{Mol}$. Endocrinol. 1992 6: 793-804

Mozes, E., Kohn, L. D., Hakim, F. and Singer, D. S. (1993) Resistance of MHC class 1. deficient Mice to experimental systemic lupus erythematosus. Science 261: 91-93

Ivashikiv, L. B. (1995) Cytokines and STATs How can signals achieve specificity? Immunity 3: 1-4

Kohn, L. D., Giuliani, C., Montani, V., Napolitano, G., Ohmori, M., Ohta, M., Saji, M., Schuppert, F., Shong, M., Suzuki, K., Taniguchi, S.-I., Yano, K. and Singer, D. S. (1995) Antireceptor immunity. In Thyroid autoimmunity (Rayner, D. C., Chamberlain,B. R. eds.), pp. 115-170, Springer RG Landers, New York

Lee, K. H., An, B. S., Lee, J. H., Ahn, M. A., Song, C. U., Shong, M. and Ro, H. K. (1996) Immunohistochemical detection and localization of intercellular adhesion molecule-1 (ICAM-1) and heat shock protein (HSP-70) in thyroid tissue from Graves' disease. Korean J. Int. Med. 50: 181-193

Martin, A., Huber, G. K. and Davies, T. F. (1990) Induction of thyroid cell ICAM-1 (CD54) antigen expression and ICAM-1 mediated lymphocyte binding. Endocrinology 127: $651-657$

Panettieri, R. A., Lazaar, A. L., Pure, E. and Albelda, S. M. (1995) Activation of cAMP dependent pathways in human airway smooth muscle cells inhibits TNF-a induced ICAM-1 and VCAM-1 expression and T lymphocyte adhesion. J. Immunol. 154: 23582365

Rothe, J. G., Loetscher, G. H. and Lesslauer, W. (1992) Tumor necrosis factor receptors: structure and function. Immunol. Res. 11: 81-90

Rothlein, R., Dustin, M. L., Marlin, S. D. and Springer, T. A. (1991) A human intercellular adhesion molecule (ICAM-1) distinct from LFA-1. J. Immunol. 137: 1270-1274

Saji, M., Moriaty, J., Ban, T., Singer, D. S. and Kohn, L. D. (1992a) Major histocompatibility complex class I gene expression in rat thyroid cells is regulated by Hormones, methimazole, and iodide as well as interferon. J. Clin. Endocrinol. Metab. 75: $871-878$

Saji, M., Akamizu, T., Sanchez, M., Ovici, S., Avvedimento, E., Gottesman, M. E. and Kohn, L. D. (1992b) Regulation of thyrotropin receptor gene expression in rat FRTL-5 thyroid cells. Endocrinology 1992 130: 520-533

Saji, M., Moriaty, J., Ban, T., Kohn, L. D. and Singer, D. (1992c) Thyrotropin regulation of MHC class I genes in rat FRTL-5 thyroid cells. Proc. Natl. Acad. Sci. USA 89: 19441948

Sharpe, A. H. (1995) Analysis of lymphocyte costimulation in vivo using transgenic and knockout mice. Curr. Biol. 7: 389-395

Shimojo, N., Kohno, Y., Yamaguchi, K.-I., Kikuoka, S.-I., Hoshioka, A., Nimi, H., Hirai, A., Tamura, Y., Saito, Y., Kohn, L. D. and Tahara, K. (1996) Induction of Graves-like disease in mice by immunization with fibroblasts transfected with the thyrotropin receptor and class II molecule. Proc. Natl. Acad. Sci.USA 93: in press

Shong, M., Ro, H. K., Kim, Y. K., Yoo, C. J., Lee, J. H., Song, C. U. and Cho, B. Y. 
(1994a) The cytokines interleukin-1beta, interleukin-6 and interferon-gamma upregulates the expression of intercellular adhesion molecule-1 (ICAM-1) in rat thyroid cell line, FRTL-5. Korean J. Int. Med. 9: 88-92

Shong, M., Ro, H. K., Kim, Y. K., Yoo, C. J., Cho, B. Y., Horiuchi, T., Hwang, B. D. and Lim, K. (1994b) Interleukin-1beta and interleukin-6 induce intercellular adhesion molecule-1 (ICAM-1) gene expression in rat thyroid cell line, FRTL-5. Korean J. Biochem. 26: 77-82

Shong, M., Taniguchi, S.-I., Napolitano, G., Saji, M., Ohmori, M., Ohta, M., Shimura, Y., Shimura, H., Singer, D. S. and Kohn, L. D. (1997) Thyroid transcription factor-1 regulation of major histocompatibility class I gene expression in thyroid cells. Mol. Endocrinol. in press

Shuai, K., Stark, G. R., Kerr, I. M. and Darnell, J. E. (1993) A single phosphotyrosine residue of stat91 required for gene activation by interferon- $\gamma$. Science 261: 1744-1746

Schutze, S., Berkovic, D., Tomsing, O., Unger, C. and Kroenke, M. (1991) Tumor necrosis factor induces rapid production of 1,2-diacylglycerol by a phosphatidylcholine specific phospholipase C. J. Exp. Med. 174: 975-988

Springer, T. A. (1990) Adhesion receptors in immune system. Nature 346: 425-433

Schutze, S., Potthoff, K., Machleidt, T., Berkovic, D., Wiegmann, K. and Kroenke, M. (1992a) TNF activates NF-KB by a phosphatidylcholine specific phospholipase C induced acidic sphingomyelin breakdown. Cell 71: 765-776

Tandon, N., Metcalfe, R. A., Barnett, D. and Weetman, A. P. (1994) Expression of the costimulatory molecule B7/BB1 in autoimmune thyroid disease. Quart. J. Med. 87: 231236

Schutze, S., Potthoff, K., Machleidt, T., Berkovic, D., Wiegmann, K. and Kroenke, M. (1992b) TNF activates NF-KB by a phosphatidylcholine specific phospholipase C induced acidic sphingomyelin breakdown. Cell 71: 765-776

Tandon, N., Dinsddale, T., Tamatani, M., Miyasaki, M. and Weetman, A. P. (1991) Adhesion molecule expression by the FRTL-5 rat thyroid cell line. J. Endocrinol. 130: 451-456

Taniguchi, S.-I., Shong, M., Giuliani, C., Saji, M., Singer, D. S. and Kohn, L. D. (1997) lodide suppression of major histocompatibility class I gene expression in thyroid cells involves enhancer $\mathrm{A}$ and the transcription factor NF- $\mathrm{KB}$. Mol. Endocrinol. in press

Tartaglia, L. A. and Goeddel, D. V. (1992) Two TNF receptors. Immunol. Today 13: $151-153$
Thompson, C. B. (1995) Distinct roles for the costimulatory ligands B7-1 and B7-2 in T helper cell differentiation. Cell 81: 979-982

Voraberger, G., Schaffer, R. and Stratobwa, C. (1991) Cloning of the human gene for the intercellular adhesion molecule-1 and analysis of its 5 '-regulatory region: induction by cytokines and phorbol ester. J. Immunol. 147: 2777-2786

Weetman, A. P. (1994) The potential immunological role of the thyroid cell in autoimmune thyroid disease. Thyroid 4: 493-499

Weetman, A. P., Freeman, M., Boryswicz, L. K. and Makoba, M. W . (1990) Functional analysis of intercellular adhesion molecule-1-expressing human thyroid cells. Eur. J. Immunol. 20: 271-275

Wen, Z., Zhong, Z. and Darnell, J. E. (1995) Maximal activation of transcription by stat1 and stat3 requires both tyrosine and serine phosphorylation. Cell 1995 82: 241-250

Wiegmann, K., Schutze, S., Kampen, A., Himmler, T., Machleidt, T. and Kroenke, M. (1992) Human $55 \mathrm{kDa}$ receptor for tumor necrosis factor coupled to signal transduction cascades. J. Biol. Chem. 267: 17997-18001

Wiegmann, K., Schutze, S., Machleidt, T., Witte, D. and Kroenke, M. (1994) Functiona dichotomy of neutral and acidic sphingomyelinase in tumor necrosis factor signaling. Cell 78: 1005-1015 